\title{
Strength quality control for ready mixed concrete
}

\author{
Mustapha Boukendakdji* \\ Department of Civil Engineering, College of Engineering, University of Hail, Hail, Saudi Arabia
}

\section{ARTICLE IN F O}

\section{Article history:}

Received 22 March 2017

Received in revised form

29 August 2017

Accepted 2 September 2017

Keywords:

Quality concrete

Variability

Compressive strength

Normal distribution

Control chart

\begin{abstract}
A B S T R A C T
The construction sector in Saudi Arabia has grown substantially in the past three decades. It is expected that the demand on concrete will increase by $10 \%$ by 2019 . The compressive strength is considered to be the most important property and it is used as an indicator to check the quality of concrete and to judge compliance with specifications. The main aim of this research is to contribute to the quality evaluation of concrete construction in the region of Hail Saudi Arabia. In this study, a statistical compressive strength, using 180 test samples after 7 and 28 days taken from different concrete constructions in the city of Hail, is analyzed using the normal distribution and control chart. For each mix, a comparison of the average value of compressive strength, standard deviations and coefficient of variation (C.V.) is made. In addition a control chart of each mix is plotted with the upper and lower limit. The results showed that, apart from two mixes, the quality ranged from good to excellent with a coefficient of variance ranging from $4.13 \%$ to $14.74 \%$. The results of compressive strength are within the upper and lower limits and no single test falls below the specified strength for all mixes. For all mixes the required average strength is 3.0 standard deviations above the specified strength, resulting in over-designed and uneconomical mixes.
\end{abstract}

(C) 2017 The Authors. Published by IASE. This is an open access article under the CC BY-NC-ND license (http://creativecommons.org/licenses/by-nc-nd/4.0/).

\section{Introduction}

The ready-mixed concrete industry in Saudi Arabia is growing rapidly. It is expected that the demand on concrete will increase by $10 \%$ by 2019 . Concrete is one of the most used materials in building and civil engineering construction works. The aim of a good quality control system is to control and minimize the variability of the concrete. Among the various properties of the hardened concrete, its compressive strength is considered to be the most important and it is used as an indicator to check the quality of concrete and to judge compliance with specifications. In the ready-mixed concrete (RMC) industry, the results of strength testing are used mainly to monitor the quality of concrete production. There are several steps and precautions that must be followed in mixing and handling fresh concrete in order to ensure a quality of concrete with the desired characteristics (Mehta and Monteiro, 2006). Concrete mix proportions have a large influence on the quality of concrete. The water-cement ratio

\footnotetext{
* Corresponding Author.

Email Address: m.boukendakdji@uoh.edu.sa (M. Boukendakdji) https://doi.org/10.21833/ijaas.2017.010.019

2313-626X/C) 2017 The Authors. Published by IASE.

This is an open access article under the CC BY-NC-ND license

(http://creativecommons.org/licenses/by-nc-nd/4.0/)
}

controls the 28- day compressive strength of concrete. The strength of concrete is also dependent on the quality of the constituent materials. Quality of concrete is also affected by other factors, such as mixing, transporting, placing, compaction, relative humidity, temperature and curing of concrete. The ready mixed concrete (RMC) companies face extra difficulties in concreting in hot weather such as slump loss. Often using an admixture or adding a small quantity of water could restore the workability. Superplasticizers can be used in the production of high strength concrete (150 MPa) owing to a very substantial reduction in the water/cement ratio (Neville, 2012).

ACI (2011) provided guidelines to evaluate data of the tests used for assessing condition of concrete. The analysis of strength test results presented in ACI (2011) assumed that test results follow normal distribution. Mathematically, normal distribution is defined by mean and standard deviation (S.D.).

This paper deals with the statistical compressive strength using 180 test samples after 7 and 28 days from different concrete constructions in the city of Hail. The main aim of this research is to contribute to the quality evaluation of concrete construction in the region of Hail Saudi Arabia. An average value of compressive strength of each mix, its standards deviation and coefficient of variation (C.V.) are 
discussed. In addition, for each mix, a control chart of the individual sample compressive strength is plotted.

\section{Variability of concrete strength}

Variations in the strength of concrete in a structure and control samples of a similar age are fundamentally due to differences in curing conditions and compaction. Variations in a concrete supply are due to the variety of batching, materials, placing and handling methods.

For a specified strength $\left(f^{\prime} c\right)$, American Concrete Institute ACI (2005) requires that the required average strength should be the maximum of the following Eqs. 1 and 2:

$\mathrm{f}^{\prime}{ }_{c r}=\mathrm{f}_{c}^{\prime}+1.34 \sigma$

$f^{\prime}{ }_{c r}=f^{\prime}{ }_{c}+2.33 \sigma-3.45$

A lower variability will result in a lower standard deviation $(\sigma)$ and a reduced target average strength $\left(f^{\prime} c r\right)$ for a specified strength $\left(f^{\prime} c\right)$.

Standard deviation is a measurement of variability or diversity in the compressive strength data. It shows how much variation or dispersion is there from the average strength. A low standard deviation value indicates the strength is more close to the mean and normal distribution curve has a steep slope. A high standard deviation shows that the compressive strength is spread out over larger range values from the average strength and normal distribution curve has a flat slope as compared to low standard deviation value.

The strength of a given concrete is considered satisfactory if both of the following requirements are met (ACI, 2005)

- The average of all sets of three consecutive tests is at least equal to the specified design strength.

- No individual strength test falls below the specified design strength by more than $3.5 \mathrm{MPa}$.

ACI (2011) Manual of Concrete Practice establishes standards of concrete control based on the standard deviation and coefficient of variance. In the category of overall variation there are five distinct classifications based on general construction testing and laboratory trial batches as show in Table 1. Coefficient of variance is a normalized measure of dispersion of a probability. It is the ratio of the standard deviation to the mean value expressed in percentage. Concrete mix design, including the selection of appropriate constituent materials, significantly influences the performance of both fresh and hardened concrete. The water/cement ratio should be less than 0.45 , and preferably around 0.40 , to obtain a durable concrete (Al-Amoudi et al., 1993). The American Concrete Institute (ACI, 2002) defines the durability of concrete as that which is able to resist weathering, chemical attack, abrasion, or other processes of deterioration. High permeability in a concrete, due to high water-cement ratio, is the main cause of durability failures (Mindess et al., 2003; Mehta and Monteiro, 2006).

Table 1: Standards of concrete control ACI (2011)

\begin{tabular}{|c|c|c|c|c|c|}
\hline \multicolumn{6}{|c|}{ Overall Variation } \\
\hline \multirow{2}{*}{ Class of Operations } & \multicolumn{5}{|c|}{ Standard Deviation for different Control Standards, MPa } \\
\hline & Excellent & Very Good & Good & Fair & Poor \\
\hline General Construction Testing & Below 2.8 & 2.8 to 3.4 & 3.4 to 4.1 & 4.1 to 4.8 & Above 4.8 \\
\hline Laboratory Trial Batches & Below 1.4 & 1.4 to 1.7 & 1.7 to 2.1 & 2.1 to 2.4 & Above 2.4 \\
\hline \multicolumn{6}{|c|}{ Within - Test Variation } \\
\hline \multirow{2}{*}{ Class of Operations } & \multicolumn{5}{|c|}{ Coefficient of Variation for different Control Standards, \% } \\
\hline & Excellent & Very Good & Good & Fair & Poor \\
\hline Field Control Testing & Below 7.0 & 7.0 to 9.0 & 9.0 to 11.0 & 11.0 to 14.0 & Above 14.0 \\
\hline Laboratory Trial Batches & Below 3.5 & 3.5 to 4.0 & 4.0 to 5.0 & 5.0 to 7.0 & Above 7.0 \\
\hline
\end{tabular}

Nowadays, concrete with a compressive strength of up to $100 \mathrm{MPa}$ can be produced commercially with an acceptable level of variability using various types of mineral and chemical admixtures, and special superplasticizer (FIP/CEB, 1990).

\section{Research methodology}

The study of concrete quality control was carried out by statistical analysis of the compression test results of specimens at 28 days of age. In this study, a statistical analysis of the concrete specimen compressive strength was performed by determining its mean value, standard deviation, coefficient of variation. Concrete strength tests were performed on six concrete mixes produced by Ready Mixed Concrete (RMC) in the region of Hail, KSA. The mix proportions of these concretes are listed in Table 2 . The cement content was from $250 \mathrm{~kg} / \mathrm{m}^{3}$ to
$475 \mathrm{~kg} / \mathrm{m}^{3}$. The water / cement ratio varies between 0.36 to 0.65 . Apart from mix1, mixes have a water/cement ratio less than 0.47 in order to fulfill the requirements of durability. If the water/cement ratio is more than 0.45 the extra water will create pores in concrete. As a result, it reduces the strength and durability of concrete.

Most of the projects used type I cement (Ordinary Portland cement) and type V (High Sulphate Resisting Portland Cement). Retardes are used in order to offset the effect of hot weather, when the normal setting time is shortened by the higher temperature. The second admixture used is supeplasticizers. They are used either to produce flowing concrete or to produce a very high strength concrete owing to a very substantial reduction in the water/cement ratio. For each sample, three cylinders (150 mm x $300 \mathrm{~mm}$ ) were tested at the age of 7 and 28 for compressive strength. 
Table 2: Concrete mixes used in the region of Hail

\begin{tabular}{ccccccc}
\hline Ingredients & Mix (1) & Mix (2) & Mix (3) & Mix (4) & Mix (5) & Mix (6) \\
\hline Cement & 250 & 350 & 380 & 425 & 420 & 475 \\
Coarse Aggr. 20 (mm) & 733 & 879 & 879 & 733 & 879 & 879 \\
Coarse Aggr. 9.5 (mm) & 314 & 377 & 377 & 314 & 377 & 377 \\
Fine Aggr. & 938 & 689 & 666 & 748 & 632 & 566 \\
Water & 185 & 184 & 199 & 199 & 183 & 189 \\
W/C ratio & 0.65 & 0.47 & 0.43 & 0.42 & 0.39 & 0.36 \\
Density & 2420 & 2479 & 2485 & 2419 & 2490 & 2486 \\
Super-Plasticizer+Retarder & $\sqrt{ }$ & $\sqrt{ }$ & $\sqrt{ }$ & $\sqrt{ }$ & $\sqrt{ }$ & $\sqrt{ }$ \\
\hline
\end{tabular}

\section{Compressive strength results and distributions}

The analysis of strength test results presented in ACI (2011) assumed that test results follow normal distribution.

The frequency distributions of compressive strength results are shown in Fig. 1 along with the means, standard deviations, coefficients of variation, and the calculated normal probability curves. Table 3 shows the basic statistical parameter (mean, standard deviation and coefficient of variation) of all mixes at 7 days and 28 days. The standard deviation varies between 1.98 and $3.72 \mathrm{MPa}$.

The standard deviations of the ready mixed concretes were between 1.98 and 3.57. The coefficient of variation varies between $6.29 \%$ and $14.74 \%$. Then the concretes are classified as poor, fair, good, very good and excellent according to the standards of control according to the values recommended by ACI (2011) (Table 3). Only one concrete mix is classified as poor concrete because the coefficient of variation is more than 14 and three concretes falls within the "excellent" (Table 3). The assessment of the concrete quality of these projects revealed that the quality ranged from poor to excellent according to ACI (2011) criteria with a Coefficient of variance ranging from $4.13 \%$ to 14.74 $\%$ (Table 3 ). The average strength at 7 days was about from $68.8 \%$ to $79.0 \%$ of that of 28 days (Table 4 and Fig. 2).

The difference between the average strength and the specified strength is from 8,8 to $11.6 \mathrm{MPa}$. It means that all types of concrete used are not economic. However these mixes used a water/cement ratio (Table 2) less than 0.5 in order to fulfill the requirements of the durability of concrete. In addition, concrete mixes are generally over-designed, for fear of producing results that do not satisfy minimum specified strength criteria.

\section{Control charts}

Control charts have been used in manufacturing industry and construction applications to verify that a process is in control. There are many types of control charts, the simplest of which plots individual results in chronological order (Mamlouk and Zaniewski, 2011).

Fig. 3 shows a control chart of the compressive strength of ready mixed concretes tested at 7 and 28 days. It can be seen that the results are within the upper and lower limits and no single test falls below the specified strength for all mixes. In addition, for all mixes the required average strength is 3.0 standard deviations above the specified strength, resulting in over-designed and uneconomical mixes.

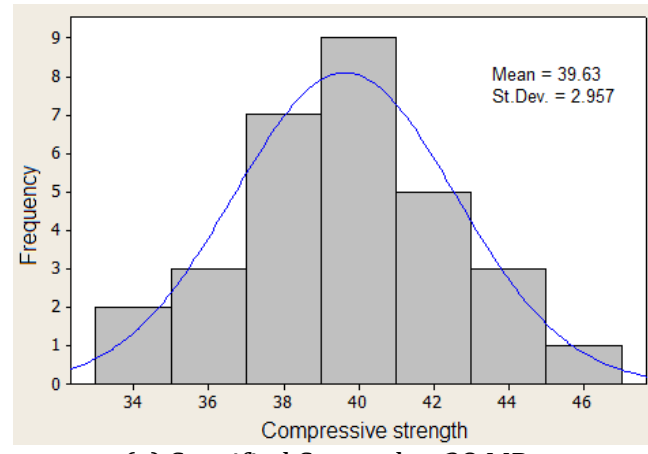

(a) Specified Strength $=28 \mathrm{MPa}$

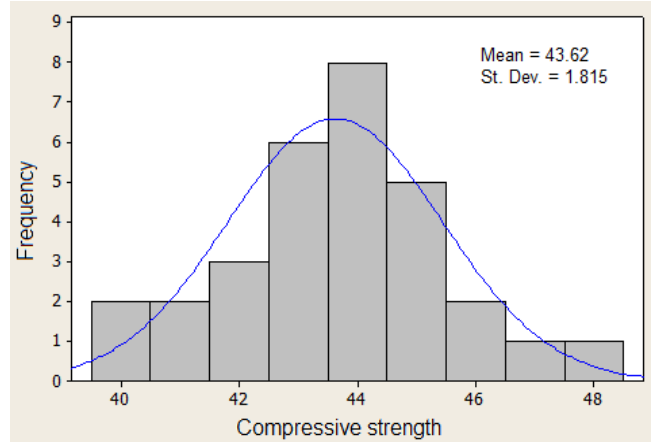

(b) Specified Strength $=32 \mathrm{MPa}$

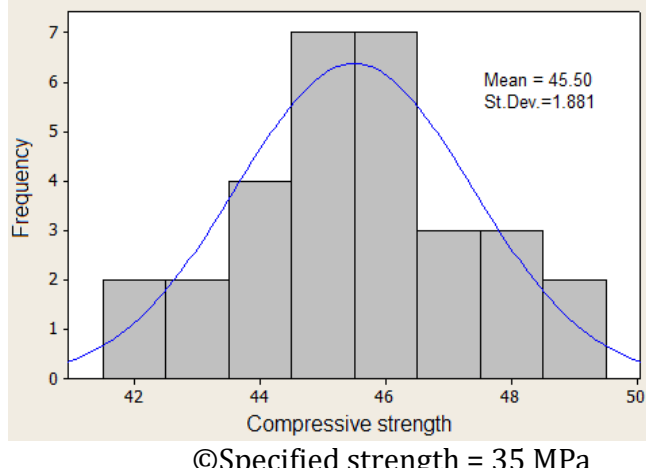

Fig. 1: The frequency distributions of concrete tested at 28 days 


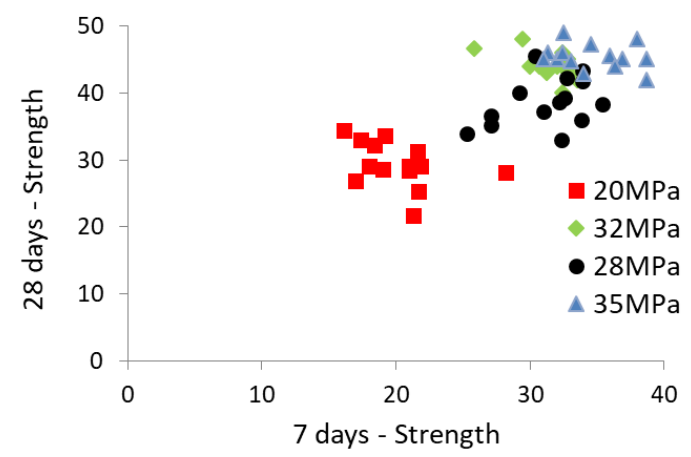

Fig. 2: Relationship between 7-days-and 28-days compressive strength

\section{Conclusion}

A statistical analysis is presented dealing with compressive strength of six ready mixed concretes. Major findings are as follows:
- The standard deviations of the ready mixed concretes were between 1.98 and 3.72. The assessment of the concrete quality of these projects revealed that the quality ranged from poor to excellent according to ACI criteria with a Coefficient of variance ranging from $4.13 \%$ to $14.74 \%$.

- The average strength at 7 days was about from 68.8 $\%$ to $79.0 \%$ of that of 28 days.

- All mixes have a water/cement ratio less than 0.5 in order to fulfill the requirements of the durability of concrete. Therefore, these mixes were overdesigned.

- The results of compressive strength are within the upper and lower limits and no single test falls below the specified strength for all mixes.

- For all mixes the required average strength is 3.0 standard deviations above the specified strength, resulting in over-designed and uneconomical mixes.

Table 3: Average strength, standard deviation and coefficient of variation of concrete tested at 7 and 28 days

\begin{tabular}{cccccc}
\hline Age (days) & Specified strength at 28 days & Average strength (MPa) & Stand. Dev. (MPa) & Coef. of var. (\%) & \\
\hline \multirow{4}{*}{7 days } & 20 & 19.8 & 2.926 & 14.74 & Poor \\
& 28 & 31.3 & 2.97 & 9.47 & Good \\
& 32 & 31.42 & 1.98 & 6.29 & Excellent \\
\multirow{5}{*}{28 days } & 35 & 34.4 & 2.67 & 7.77 & Very Good \\
& 20 & 28.8 & 3.57 & 12.39 & Fair \\
& 28 & 39.63 & 2.967 & 7.49 & Very Good \\
& 32 & 43.62 & 1.815 & 4.16 & Excellent \\
S2 & 45.50 & 1.881 & 4.13 & Excellent \\
\hline
\end{tabular}

Table 4: Ratio between concrete strength at 7 days and 28 days

\begin{tabular}{cccc}
\multicolumn{4}{c}{ Table 4: Ratio between concrete strength at 7 days and 28 days } \\
\hline \multirow{2}{*}{ Specified strength at 28 days } & Average strength MPa at 7 days & Average strength MPa at 28 days & $\frac{\text { strengthat 7 days }}{\text { strength at 28 days }} \times 100$ \\
\hline 20 & 19.8 & 28.8 & $68.8 \%$ \\
28 & 31.3 & 39.63 & $79.0 \%$ \\
32 & 31.42 & 43.62 & $72.0 \%$ \\
35 & 34.4 & 45.50 & $75.6 \%$ \\
\hline
\end{tabular}

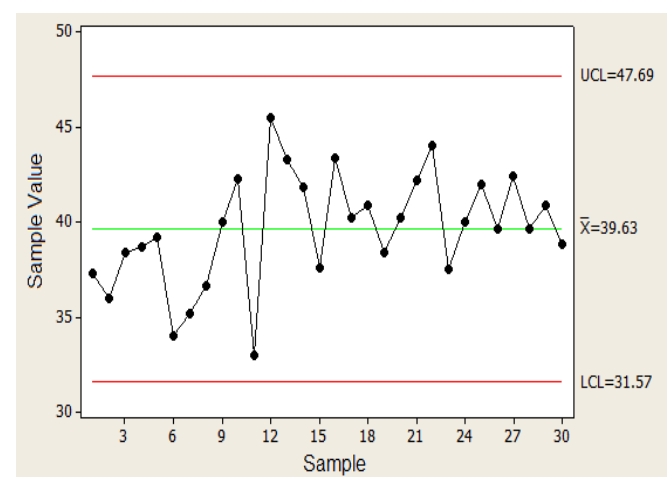

(a) Specified Strength $=28 \mathrm{MPa}$

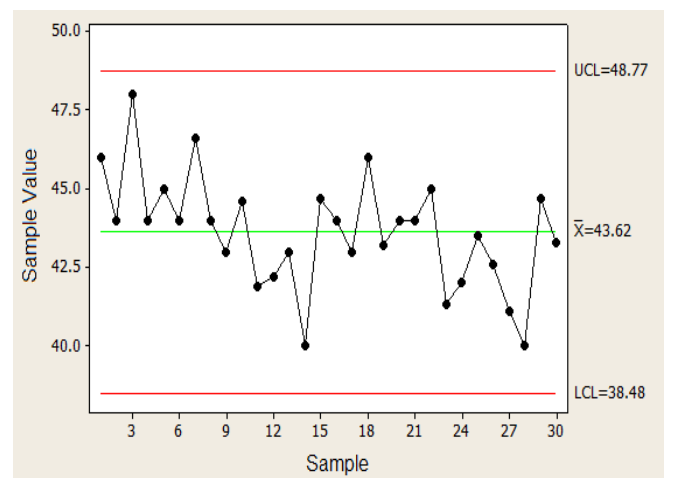

(b) Specified Strength $=32 \mathrm{MPa}$

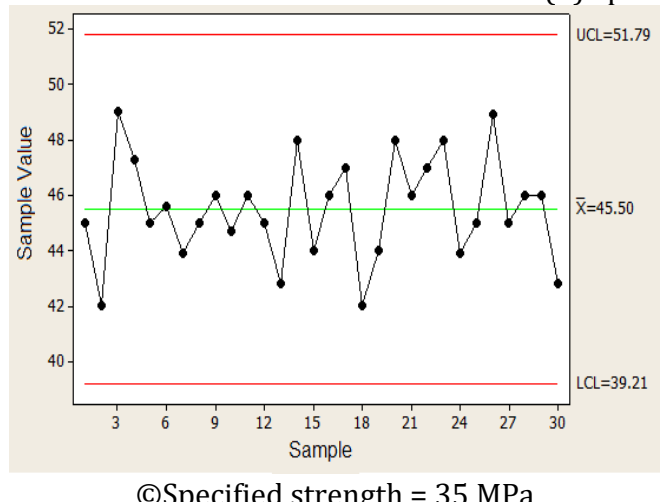

Fig. 3: Control Chart for all concretes tested at 28 days 


\section{Acknowledgment}

The research reported herein was funded by the Deanship of Scientific Research at the University of Hail, Saudi Arabia, under the contract (E-10-CE). The authors would like to express their deepest gratitude to the Deanship of Scientific Research and to the College of Engineering at the University of Hail for providing necessary support to conducting this research.

\section{References}

ACI (2002). ACI Committee 201: Guide to durable concrete (ACI 201.2R-92). American Concrete Institute. Farmington Hills, USA.

ACI (2005). ACI Committee 318: Building code requirements for structural concrete and commentary. American Concrete Institute, Farmington Hills, USA.
ACI (2011). ACI Committee 214: Guide to evaluation of strength test results of concrete (ACI 214R-11). American Concrete Institute, Farmington Hills, USA.

Al-Amoudi OSB, Maslehuddin M, and Zafar RU (1993). Permeability of Concrete: Influential Factors. In the Conference of $4^{\text {th }}$ International Conference on Deterioration and Repair of Reinforced Concrete in the Arabian Gulf, Bahrain: 717-733.

CEB-FIP (1990). Applications of high performance concrete (Bulletin d' Information No. 222). Comité Euro-International du Béton-Fédération Internationale de la Précontraint. Lausanne, Switzerlaand.

Mamlouk MS and Zaniewski JP (2011). Materials for civil and construction engineers. Prentice Hall, Upper Saddle River, USA.

Mehta PK and Monteiro PJM (2006). Concrete: microstructure, properties, and materials. McGraw-Hill, New York, USA.

Mindess S, Young JF, and Darwin D (2003). Concrete. Pearson Education, Upper Saddle River, USA.

Neville AM (2012). Properties of concrete. Prentice Hall, Pearson, San Francisco, USA. 